Review began 11/15/2021 Review ended 11/19/2021 Published 11/21/2021

(c) Copyright 2021

Senapati et al. This is an open access article distributed under the terms of the Creative Commons Attribution License CC BY 4.0., which permits unrestricted use, distribution, and reproduction in any medium, provided the original author and source are credited.

\section{Effect of Non-depolarizing Muscle Relaxants Rocuronium Versus Vecuronium in the Assessment of Post-Succinylcholine Complications in Surgeries Under General Anesthesia: A Randomized Double-Blind Study at a Tertiary Care Hospital}

Laxman K. Senapati ${ }^{1}$, Krishna P. Battini ${ }^{1}$, Pulak P. Padhi ${ }^{1}$, Priyadarsini Samanta ${ }^{2}$

1. Department of Anesthesia, Kalinga Institute of Medical Sciences, KIIT Deemed to be University, Bhubaneswar, IND

2. Department of Physiology, Kalinga Institute of Medical Sciences, KIIT Deemed to be University, Bhubaneswar, IND

Corresponding author: Priyadarsini Samanta, dr.priyasamanta@gmail.com

\section{Abstract \\ Background and objective}

Several drugs have been used to prevent or attenuate succinylcholine-induced muscle fasciculations and myalgia. We designed the present study to evaluate the efficacy of rocuronium (ROC) and vecuronium (VEC) in preventing succinylcholine-induced fasciculations and postoperative myalgia (POM) in patients undergoing surgery under general anesthesia.

\section{Materials and methods}

After obtaining written informed consent, 125 patients were randomly selected to receive either ROC 0.06 $\mathrm{mg} / \mathrm{kg}$ or VEC $0.01 \mathrm{mg} / \mathrm{kg}$, with both diluted up to $2 \mathrm{ml}, 90$ seconds before the administration of propofol followed by succinylcholine. A standardized balanced anesthetic technique was used for all patients. The intensity of fasciculations and intubating conditions were assessed using a 4-point rating scale. All patients were evaluated up to the third postoperative day for the presence of $\mathrm{POM}$, the severity of which was graded on a 4-point scale.

\section{Results}

The incidence of post-succinylcholine fasciculations during induction was nil in $74.58 \%$ of patients in the ROC group and $51.52 \%$ in the VEC group. Mild fasciculation was seen in $22.03 \%$ in the ROC group and $33.33 \%$ in the VEC group. Moderate fasciculation was seen in $3.39 \%$ and $15.15 \%$ in ROC and VEC groups respectively. When comparing both the groups, a significant decrease $(p=0.015)$ in intraoperative fasciculation was observed in the ROC group than in the VEC group. Both drugs provided good intubating conditions without any statistical significance and with an overall intubating score of 8-9 in both groups as per Lund. On day one, $91.53 \%(n=54)$ of the ROC group and $65.15 \%(n=43)$ of the VEC group patients did not have any myalgia symptoms. Mild myalgia was observed in $8.47 \%(n=5)$ in the ROC group and $31.82 \%(n=21)$ in the VEC group, and only $1.8 \%$ had moderate myalgia in the VEC group. The results of the study showed that POM was significantly decreased in the ROC group than in the VEC group on day one $(\mathrm{p}=0.001)$. The incidence of POM on day two was significantly low in both groups. There was no statistical significance between the two groups based on Fisher's exact test $(\mathrm{p}=1.000)$. None of the patients had myalgia on day three.

\section{Conclusion}

Our results showed that the incidence and severity of fasciculations and POM were significantly decreased by pretreatment with ROC in contrast to that with VEC. Hence, ROC is a better option than VEC to combat succinylcholine-related complications like fasciculation and myalgia.

Categories: Anesthesiology

Keywords: myalgia, fasciculations, intubation, succinylcholine, vecuronium, rocuronium, nondepolarizing muscle relaxants

\section{Introduction}

During rapid sequence intubation, succinylcholine plays a pivotal role in administering general anesthesia as it produces profound and quick neuromuscular block within 30 to 60 seconds, which lasts for three to five minutes [1]. It is a life-saving drug in cases of difficult intubation or failed intubation scenarios owing to its 
short half-life.

However, its helpfulness is often accompanied by the persistent manifestation of postoperative myalgia (POM) besides other plethora of side effects such as persistent neuromuscular blocks in patients with pseudocholinesterase deficiency, malignant hyperthermia, and rhabdomyolysis in patients with myopathy [2]. The incidence of succinylcholine-induced myalgia ranges from 20 to $80 \%$ [3]. It usually lasts from two or three days to as long as a week and is most notable in the muscles of the neck, back, and abdomen $[4,5]$. In the contemporary practice of anesthesia, myalgia is insufferable even though it perishes on its own [6].

To decrease the incidence and severity of myalgia, various treatment methods have been recommended, which includes lignocaine [7], diazepam, ketorolac, diclofenac [8], gabapentin, remifentanil, cisatracurium [9], d-tubocurarine, pancuronium, vecuronium (VEC) [10], rocuronium (ROC) [11], and atracurium [12]. Among these options, pretreatment with a small dose of the non-depolarising neuromuscular drug before succinylcholine administration is the most effective [13]. The efficacy of the pretreatment is determined by the choice of the non-depolarizing agent $[14,15]$, the extent of prejunctional receptor block, the time gap between the administration of the pretreatment agent and succinylcholine, and the speed of onset of the non-depolarising drug.

As opposed to all the commonly used non-depolarising agents, the onset of action of ROC is very rapid and it generates perfect intubating condition within 60 seconds [16]. The frequency and severity of fasciculations are markedly reduced by pretreatment with ROC 90 seconds before succinylcholine administration [17]. Schreiber et al. [18] have established that ROC and non-steroidal anti-inflammatory agents are the prime agents to prevent fasciculation and myalgia induced by succinylcholine, based on a meta-analysis of randomized trials.

To date, there have been limited studies on the occurrence and severity of myalgia up to the third postoperative day following succinylcholine administration. Hence, the present research was undertaken to compare the effect of pretreatment with ROC, the near-ideal muscle relaxant, with that with VEC, an already established neuromuscular blocking agent for post-succinylcholine complications such as fasciculations and myalgia up to the third postoperative day. We also tried to assess if there were any differences between the intubating conditions produced by the two drugs.

\section{Materials And Methods \\ Study participants and study design}

Considering an effect size of 0.5 , power (1- $\beta$ ) of 0.80 , a $5 \%$ level of significance, and an attrition rate of $5 \%$, the calculated total sample size was 132 , i.e., 66 in each group. After obtaining approval from the Institutional ethics committee (KIIT/KIMS/IEC/128/2019, CTRI no: CTRI/2019/10/021820) and receiving written informed consent, a randomized double-blind study was conducted with 125 patients (excluding seven patients lost to follow-up) from September 2019 to September 2021; the patients were categorized into in two groups (59 in the ROC group and 66 in the VEC group). The study was conducted at the tertiary care center of Pradyumna Bal Memorial Hospital, Kalinga Institute of Medical Sciences (KIMS), Bhubaneswar, Odisha. Patients aged 16-80 years, with the American Society of Anesthesiologists (ASA) physical status I and II, who were undergoing elective surgery under general anesthesia with endotracheal intubation of a duration of at least 30 minutes were included in our study. Patients having body mass index (BMI) $\geqslant 30$, history of allergy to any particular drugs used in the study, pregnant patients, those with post-burn, posttrauma, and other hyperkalemic states, those with an anticipated difficult airway, those with hepatic or renal dysfunction and increased intraocular or intracranial pressure were excluded.

Randomization was done by a computer-generated randomization list and allocation was done by sequentially numbered opaque envelopes to one of the two groups (ROC group and VEC group). The envelope was opened by an anesthetist just before administering the drug. A double-blinding technique was followed, where an anesthesiologist who was not part of the study prepared the solution in a standardized volume of 2-ml syringes. The observer and the patients were unaware of the pretreatment used.

\section{Anesthetic technique}

Injection glycopyrrolate $0.2 \mathrm{mg}$ IV, injection midazolam $1 \mathrm{mg}$ IV, and injection nalbuphine $0.1 \mathrm{mg} / \mathrm{kg}$ IV were administered as premedication; the standard anesthetic technique was followed in all patients, and electrocardiography, oxygen saturation, and non-invasive blood pressure monitoring were carried out. The two groups were as follows: the ROC group received $0.06 \mathrm{mg} / \mathrm{kg}$ of ROC IV diluted up to $2 \mathrm{ml}$ and the VEC group received $0.01 \mathrm{mg} / \mathrm{kg}$ of VEC IV diluted up to $2 \mathrm{ml}$. After 90 seconds, the patients were induced with propofol $1.5-2 \mathrm{mg} / \mathrm{kg}$ IV and succinylcholine $1.5 \mathrm{mg} / \mathrm{kg}$ IV. Direct laryngoscopy was performed one minute after the administration of succinylcholine and the patient's trachea was intubated via oral route in the sniffing position with an endotracheal tube of appropriate size. The laryngoscopy was carried out by an experienced anesthesiologist in all patients to assess the intubating conditions; the anesthesiologist was blinded to the pretreatment group. 
Intraoperatively, anesthesia was maintained with isoflurane (0.5-1.5\% end-tidal concentrations) along with nitrous oxide $60 \%$ in oxygen and intermittent doses of VEC or ROC. Patients were ventilated in the volume control mode of ventilation to achieve an end-tidal $\mathrm{CO}_{2}$ concentration of 35-40 mmHg. Intraoperative analgesia was provided with IV paracetamol $1 \mathrm{gm}$. At the end of the surgery, residual neuromuscular blockade was reversed with injection glycopyrrolate $10 \mathrm{mcg} / \mathrm{kg}$ and injection neostigmine $0.05 \mathrm{mg} / \mathrm{kg}$. After complete recovery, all patients were extubated and shifted to the post-anesthesia care unit (PACU).

\section{Assessment of fasciculations, myalgia, and intubating conditions}

The severity of fasciculation was assessed on a 4-point scale (Foster, 1960) [19], by an anesthesiologist blinded to the patient's group assignment, where $0=$ nil fasciculations; $1=$ mild, fine fasciculations of the eyes, neck, face, or fingers without limb movement; $2=$ moderate fasciculations occurring at more than two sites or obvious limb movement; and $3=$ vigorous or severe, sustained, and widespread fasciculations in the trunk and limbs.

Intubating conditions were assessed as per guidelines by Lund (1970) [20], where a score of $3=$ good jaw relaxation, vocal cords open, and immobile with no response to intubation; a score of $2=$ moderate jaw relaxation, vocal cords moving and slight diaphragmatic movements in response to intubation; a score of $1=$ minimum jaw relaxation, vocal cords closing, and mild coughing in response to intubation; and a score of $0=$ poor jaw relaxation, closed vocal cords, and severe coughing in response to intubation. The total score for intubation was categorized as follows: excellent=8-9, good=6-7, fair=3-5, and poor=0-2 (Lund, 1970) [20].

Myalgia was also graded on a 4-point scale (White, 1962) [21] on day one, day two, and day three postoperatively and was assessed by another investigator who was unaware of the group details, where nil=no muscle pain; mild=muscle stiffness or pain, when specifically enquired in the nape of the neck, or the shoulders and lower chest on deep breathing; moderate=muscle stiffness and pain spontaneously complained of by the patient that needs analgesics; and severe=incapacitating generalized muscle stiffness or pain.

\section{Statistical analysis}

IBM SPSS Statistics software version 23.0 (IBM, Armonk, NY) was used for all analyses. All categorical variables were expressed as frequency and percentages. The continuous variables of the data were presented as mean \pm standard deviation. The Fisher's exact test was applied to compare and assess the significance of the difference in the mean values of variables between the two groups (the ROC group and the VEC group). A p-value of $<0.05$ was considered statistically significant.

\section{Results}

A total of 132 patients were eligible for the study, but 125 patients were finally included in the study since seven patients in the ROC group were lost to follow-up (Figure 1). 


\section{Cureus}

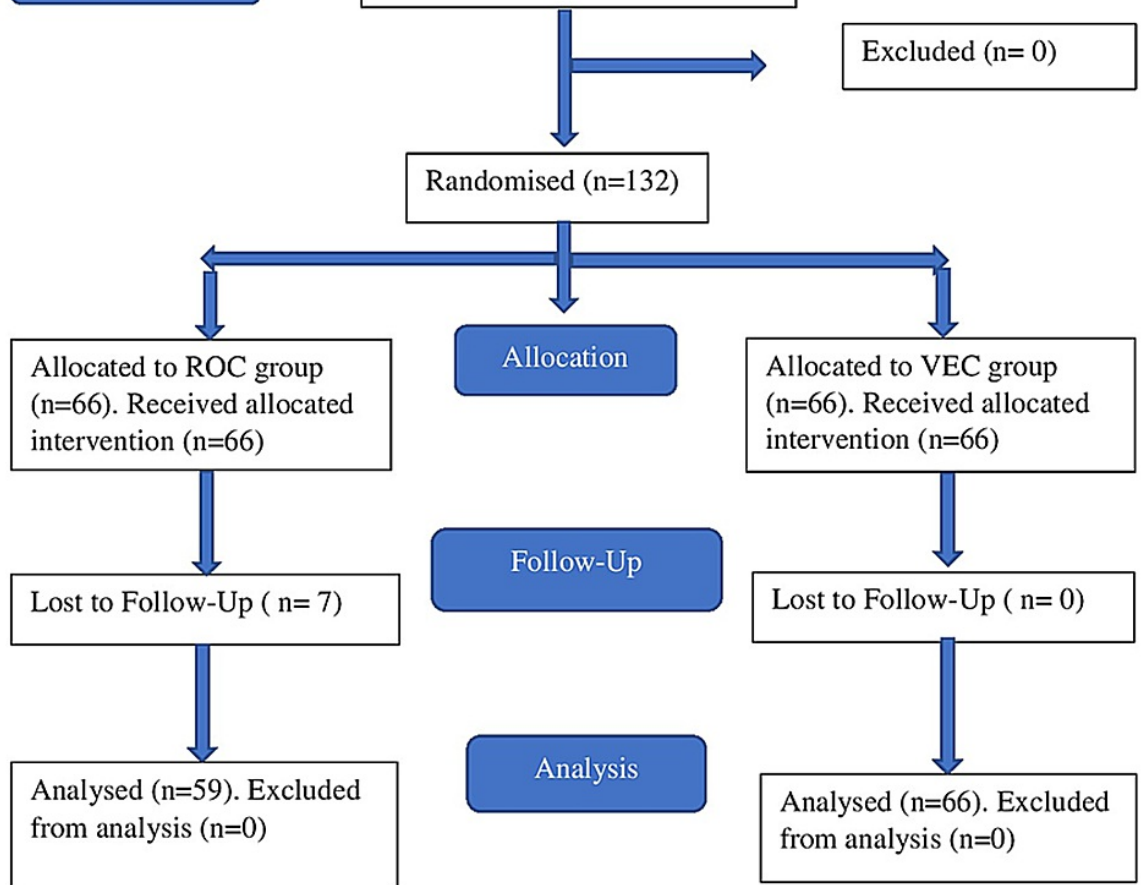

\section{FIGURE 1: CONSORT study flow chart}

CONSORT: Consolidated Standards of Reporting Trials; ROC: rocuronium group; VEC: vecuronium group

\section{Demographic variables}

A total of 125 patients were included in the study to observe the incidence of fasciculation and myalgia. No significant differences in terms of age, weight, ASA status, MP grade, and dose of succinylcholine were observed between the two groups (Tables 1-5).

\begin{tabular}{|c|c|c|c|}
\hline & $\operatorname{ROC}(n=59)$ & $\operatorname{VEC}(n=66)$ & P-value \\
\hline Age, years, mean $\pm S D$ & $39.45 \pm 11.85$ & $39.59 \pm 11.78$ & 0.949 \\
\hline Weight, $\mathrm{kg}$, mean $\pm \mathrm{SD}$ & $61.94 \pm 10.96$ & $63.4 \pm 11.22$ & 0.464 \\
\hline
\end{tabular}

TABLE 1: Age and weight distribution between two groups

ROC: rocuronium group; VEC: vecuronium group; SD: standard deviation 


\section{Cureus}

\begin{tabular}{|c|c|c|c|c|}
\hline \multirow{2}{*}{ Gender } & \multicolumn{2}{|l|}{ Group } & \multirow{2}{*}{ Total, $\mathrm{n}$ (\%) } & \multirow{2}{*}{ P-value } \\
\hline & ROC, n (\%) & VEC, $\mathrm{n}(\%)$ & & \\
\hline Male & $22(37.3)$ & $33(50)$ & 55 (44) & \multirow{3}{*}{0.153} \\
\hline Female & $37(62.7)$ & $33(50)$ & $70(56)$ & \\
\hline Total & 59 & 66 & 130 & \\
\hline
\end{tabular}

\section{TABLE 2: Gender distribution between two groups}

ROC: rocuronium group; VEC: vecuronium group

\begin{tabular}{|c|c|c|c|c|}
\hline \multirow{2}{*}{ ASA grade } & \multicolumn{2}{|l|}{ Group } & \multirow{2}{*}{ Total, $\mathrm{n}(\%)$} & \multirow{2}{*}{ P-value } \\
\hline & ROC, n (\%) & VEC, $n(\%)$ & & \\
\hline 1 & $39(66.1)$ & $41(62.1)$ & $80(64)$ & \multirow{3}{*}{0.643} \\
\hline " & $20(33.9)$ & $25(37.9)$ & $45(36)$ & \\
\hline Total & 59 & 66 & 125 & \\
\hline
\end{tabular}

\section{TABLE 3: ASA grade distribution between two groups}

ASA: American Society of Anesthesiologists; ROC: rocuronium group; VEC: vecuronium group

\begin{tabular}{|c|c|c|c|c|}
\hline \multirow{2}{*}{ MP grade } & \multicolumn{2}{|l|}{ Group } & \multirow{2}{*}{ Total, $\mathbf{n}(\%)$} & \multirow{2}{*}{ P-value } \\
\hline & ROC, $\mathrm{n}(\%)$ & VEC, $\mathrm{n}(\%)$ & & \\
\hline 1 & $33(55.9)$ & $30(45.5)$ & $63(50.4)$ & \\
\hline 2 & $26(44.1)$ & $36(54.5)$ & $62(49.6)$ & 0.242 \\
\hline Total & 59 & 66 & 125 & \\
\hline
\end{tabular}

TABLE 4: MP grade distribution between two groups

ROC: rocuronium group; VEC: vecuronium group

\begin{tabular}{|l|l|l|}
\hline \hline & ROC & VEC \\
\hline Dose of succinylcholine, mg, mean \pm SD & $92.31 \pm 16.15$ & $95.72 \pm 15.01$ \\
\hline
\end{tabular}

\section{Incidence of fasciculations}

Out of 125 patients, $62.4 \%(n=78)$ had no fasciculations while $28 \%(n=35)$ had grade 1 fasciculations and $9.6 \%(n=12)$ had grade 2 fasciculations. Grade 1 and grade 2 fasciculations were considered to be mild and moderate respectively (Table 6 ). 


\section{Cureus}

\begin{tabular}{|l|l|l|}
\hline Grades of intraoperative fasciculation & Number of patients & Percentage \\
\hline Nil & 78 & 62.40 \\
\hline Mild & 35 & 28.00 \\
\hline Moderate & 12 & 9.60 \\
\hline Severe & 0 & 0 \\
\hline
\end{tabular}

TABLE 6: Gradation of intraoperative fasciculation based on incidences of fasciculation

Comparative Incidence of Fasciculations in ROC vs. VEC

The incidence of intraoperative fasciculations was nil in $74.58 \%$ of patients in the ROC group and $51.52 \%$ in the VEC group. Mild fasciculation was seen in $22.03 \%$ in the ROC group and $33.33 \%$ in the VEC group. Moderate fasciculation was seen in $3.39 \%$ and $15.15 \%$ in ROC and VEC groups respectively. When comparing both the groups, a significant decrease $(\mathrm{p}=0.015)$ in intraoperative fasciculation was observed in the ROC group than in the VEC group (Table 7).

\begin{tabular}{|c|c|c|c|}
\hline Grades of intraoperative fasciculation & ROC (\%) & VEC (\%) & Total (\%) \\
\hline Nil & 74.58 & 51.52 & 62.40 \\
\hline Mild & 22.03 & 33.33 & 28.00 \\
\hline Modera & 3.39 & 15.15 & 9.60 \\
\hline
\end{tabular}

TABLE 7: Percentage of the severity of fasciculations in each group

ROC: rocuronium group; VEC: vecuronium group

\section{Intubation condition}

An intubation score of 9 as per Lund [20] was observed in 55\% of the ROC group and 50\% of the VEC group of patients. There was no statistically significant difference with regard to the mean intubation score between the two groups. We were able to intubate most of the patients with ease since both the drugs led to excellent intubating conditions (Tables 8, 9). 


\section{Cureus}

\begin{tabular}{|c|c|c|c|c|}
\hline \multirow{2}{*}{ Intubation score } & \multicolumn{2}{|l|}{ ROC } & \multicolumn{2}{|l|}{ VEC } \\
\hline & Number of patients & Percentage & Number of patients & Percentage \\
\hline 10 & - & - & - & - \\
\hline 9 & 32 & $55 \%$ & 33 & $50 \%$ \\
\hline 8 & 16 & $27 \%$ & 18 & $28 \%$ \\
\hline 7 & 8 & $13 \%$ & 7 & $11 \%$ \\
\hline 6 & 3 & $5 \%$ & 6 & $9 \%$ \\
\hline 5 & - & - & 2 & $2 \%$ \\
\hline Less than 4 & - & - & - & - \\
\hline Total & & 59 & & 66 \\
\hline Mean $\pm S D$ & $8.30 \pm 0.89$ & & & $8.12 \pm 1.11$ \\
\hline
\end{tabular}

\section{TABLE 8: Intubation condition scores between two groups}

ROC: rocuronium group; VEC: vecuronium group; SD: standard deviation

\begin{tabular}{|c|c|c|c|c|}
\hline \multirow{2}{*}{ Intubating condition } & \multicolumn{2}{|l|}{ ROC } & \multicolumn{2}{|l|}{ VEC } \\
\hline & Number of patients & Percentage & Number of patients & Percentage \\
\hline Excellent & 47 & $80 \%$ & 50 & $76 \%$ \\
\hline Good & 12 & $20 \%$ & 15 & $22 \%$ \\
\hline Fair & - & - & 1 & $2 \%$ \\
\hline Poor & - & - & & \\
\hline Total & 59 & & 66 & \\
\hline
\end{tabular}

\section{TABLE 9: Intubating condition}

ROC: rocuronium group; VEC: vecuronium group

\section{Incidence of myalgia}

The incidence of myalgia was monitored on three consecutive days (days one, two, and three) postoperatively. Among 125 patients, the incidence of myalgia was nil in $77.6 \%$ of patients on day one, and on the second day, $99.2 \%$ had no incidence of myalgia. Mild myalgia was observed in $20.8 \%$ on day one, and only $0.8 \%$ had mild myalgia on the second postoperative day (Table 10 ). The incidence of moderate myalgia was $1.6 \%$ and $0.8 \%$ on days one and two respectively. None of the patients in the sample group had severe myalgia. The incidence of myalgia was zero in both groups on day three. 


\section{Cureus}

\begin{tabular}{|c|c|c|c|}
\hline Day 1 & Frequency & Percentage & Cumulative percentage \\
\hline Nil & 97 & 77.60 & 77.60 \\
\hline Mild & 26 & 20.80 & 98.40 \\
\hline Moderate & 2 & 1.60 & 100.00 \\
\hline Day 2 & Frequency & Percentage & Cumulative percentage \\
\hline Niil & 124 & 99.20 & 99.20 \\
\hline Mild & 1 & 0.80 & 100.00 \\
\hline
\end{tabular}

TABLE 10: Incidence of postoperative myalgia with mild and moderate grades

Comparative Incidence of Myalgia in ROC vs. VEC Group of Patients on Day One

The incidence of POM was recorded for up to three days between two groups (ROC and VEC). On day one, $91.53 \%(n=54)$ of the ROC group and $65.15 \%(n=43)$ of the VEC group of patients did not have any myalgia symptoms. Mild myalgia was observed in $8.47 \%(n=5)$ in the ROC group and $31.82 \%(n=21)$ in the VEC group, and only $1.8 \%$ had moderate myalgia in the VEC group. The results of the study showed that POM was significantly decreased in the ROC group than in the VEC group ( $\mathrm{p}=0.001)$ (Table 11).

\begin{tabular}{|c|c|c|c|}
\hline Grades of myalgia & ROC (\%) & VEC (\%) & Total (\%) \\
\hline Nil & 91.53 & 65.15 & 77.60 \\
\hline Mild & 8.47 & 31.82 & 20.80 \\
\hline Moderate & 0.00 & 3.03 & 1.60 \\
\hline
\end{tabular}

\section{TABLE 11: Comparative incidences of postoperative myalgia on day one}

ROC: rocuronium group; VEC: vecuronium group

Comparative Incidence of Myalgia in ROC vs. VEC Group of Patients on Day Two

The incidence of POM on day two was significantly less in both groups. There was no statistically significant difference between the two groups based on Fischer's exact test ( $\mathrm{p}=1.000)$ (Table 12).

\begin{tabular}{|c|c|c|c|}
\hline gia & ROC (\%) & VEC (\%) & Total (\%) \\
\hline Nil & 100.00 & 98.48 & 99.20 \\
\hline Mild & 0.00 & 1.52 & 0.80 \\
\hline
\end{tabular}

\section{TABLE 12: Comparative incidences of postoperative myalgia on day two}

ROC: rocuronium group; VEC: vecuronium group

\section{Discussion}

VEC was described as the best pretreatment agent in preventing succinylcholine-induced complications $[14,15]$; in light of this, we engaged in a study to compare ROC with VEC. We used a VEC dose of $1 \mathrm{mg}$ based on previous observations [15] and the dose of ROC was determined to be $6 \mathrm{mg}$ based on potency ratio. The administration of pretreatment agents both on a fixed drug regimen [15,22] and on the basis of weight [23] has been postulated and we preferred dosing as per weight to maintain uniformity. Kim et al. [11] in their study used different precurarization doses of ROC, of which a dose of $0.06 \mathrm{mg} / \mathrm{kg}$ resulted in less incidence of fasciculations, with the acceptable onset of actions. Hence, we took the precurarization dose of ROC to be 
Of late, there has been a lot of debate regarding the time interval between the administration of pretreatment agents and succinylcholine. Intervals of two, three, and four minutes or longer have been proposed $[21,27,28]$. But these prolonged intervals are not only impractical with busy operating room lists but may also expose the awake patient to the potentially unpleasant experiences of difficulty in swallowing, breathing, and muscle weakness, and may also lead to desaturation of the patient because of the longer apnea time. To avoid these hazards, we chose 90 seconds of rapid precurarizing time, which reduces the possibility of exposing the patients to the side effects of precurarization.

\section{Fasciculations}

The severity of fasciculation was comparatively low in the ROC group than in the VEC group. In the ROC group, incidence of grade 1 (mild) fasciculation was $10.4 \%(\mathrm{n}=13)$ and that of grade 2 (moderate) was $1.6 \%$ $(n=2)$. The incidence of grade 1 and grade 2 fasciculations in the VEC group was $17.6 \%(n=22)$ and $8 \%(n=10)$ respectively. It was discovered that the efficacy of preventing succinylcholine-induced fasciculations relies upon the level of affinity of non-depolarising muscle relaxants for prejunctional choline receptors [29]. Higher affinity was found with ROC, which explains its better effectiveness.

In a study conducted by Joshi et al. [30], the incidence of fasciculations was $24 \%$ with ROC and $48 \%$ with VEC, with a 100\% incidence rate in the control group (normal saline). In a study by Abbas et al. [31] using 0.1 $\mathrm{mg} / \mathrm{kg}$ of ROC as pretreatment, $100 \%$ (mild to severe) fasciculations were noticed in the saline group as compared to $13.3 \%$ (mild) in the ROC group. Abraham et al. [32] found that fasciculations after succinylcholine administration was less in the ROC group $(0.06 \mathrm{mg} / \mathrm{kg})$ compared to the VEC group $(0.04$ $\mathrm{mg} / \mathrm{kg}$ ), which also correlates with our study.

Demers-Pelletier et al. [33] reported in their study that post-succinylcholine fasciculations were more intense in saline groups as compared to pretreatment with ROC $(\mathrm{p}<0.001)$ group. Findlay and Spittal [34] found that fasciculation in the group precurarized with VEC was more when compared to ROC $(\mathrm{p}<0.01)$. In a study by Martin et al. [35], it was seen that ROC was the best option to prevent muscular fasciculations following succinylcholine injection among d-tubocurarine, VEC, mivacurium, atracurium, and ROC. Joshi et al. [9] ascertained that fasciculations were observed less frequently $(\mathrm{p}<0.05)$ in the d-tubocurarine and ROC groups compared with the placebo and cisatracurium groups. Our findings are in line with all of the above studies.

\section{Intubating conditions}

In our study, it was observed that pretreatment with either ROC or VEC provided good intubating conditions without any statistically significant difference, with an overall intubation score of $8.30 \pm 0.89$ in the ROC group and $8.12 \pm 1.11$ in the VEC group.

O'Sullivan et al. [36], Findlay and Spittal [34], Tsui et al. [37], and Martin et al. [35] utilized ROC and VEC pretreatment before the administration of succinylcholine for endotracheal intubation. They could not find any dissimilarity in intubation conditions in their patients, which endorses the findings of our study.

\section{Postoperative myalgia}

In our study, the overall occurrence of myalgia on postoperative day one was found to be $21.8 \%$ and negligible on day two and day three. The severity of POM was less with ROC than VEC. We observed that the incidence of mild myalgia in the ROC group was $4 \%$ on day one, and it was $16 \%$ in the VEC group, which was statistically significant $(\mathrm{p}=0.001)$. The incidence of moderate myalgia in the VEC group was $1.6 \%$ on day one and zero in the ROC group, which was also statistically significant $(\mathrm{p}=0.001)$. The myalgia on postoperative day two and day three did not show any statistical significance between the two groups.

In a study conducted by Joshi et al. [30], the incidence of mild to moderate myalgia was found to be higher in the VEC group when compared to the ROC group. Our findings concur with those of O'Sullivan et al. [36] and Erkola [14]. Findlay and Spittal [34] could not find any statistically significant difference between the ROC and VEC groups on the occurrence of myalgia on the third postoperative day, which concurs with our study.

Waters and Mapleson [38] put forward that myalgia occurs because of the damage produced in muscles by the unsynchronized contraction of adjacent muscle fibers just before the onset of paralysis leading to shearing of connective tissues, the other reasons being the release of prostaglandins and electrolyte imbalance. But the association between fasciculations and myalgia has not been elucidated by many researchers. Hence, pretreatment with non-depolarizing agents subdues the adverse action of succinylcholine at the neuromuscular junction.

\section{Limitations}

The limitation of our study is that we could have included a saline group as controls and compared both the 
drugs with it. But we felt that it would be unethical to use saline instead of proven drugs in patients and thereby put them in jeopardy of the potential complications of succinylcholine.

\section{Conclusions}

The occurrence and severity of fasciculations were significantly less in the ROC group in contrast with the VEC group. Both of the drugs produced excellent intubating conditions. Similarly, the incidence and seriousness of POM on day one were remarkably less in the ROC group than in the VEC group. But on the second postoperative day, the incidence of myalgia was similar in both groups. No patients complained of myalgia on the third postoperative day. Hence, ROC is better than VEC to combat succinylcholine-induced complications like fasciculation and myalgia and it produced rapid precurarization in one minute, thereby minimizing the unpleasant experience of partial neuromuscular blockade from precurarization. Reduced myalgia promotes early patient ambulation, leads to fewer postoperative complications like deep vein thrombosis, and results in faster discharge from the hospital. We propose that ROC is cost-effective due to reduced postoperative analgesic requirements resulting in early ambulation. Even though it is not standard practice, the use of ROC is advocated before succinylcholine to negate the side effects while taking advantage of its plethora of benefits in various elective surgeries.

Even with the advent of newer drugs with better pharmacological profiles, the advantages of succinylcholine cannot be underestimated. The rapid and excellent intubating conditions achieved by succinylcholine are unparalleled. Hence, this study could also be extrapolated to patients needing succinylcholine for rapid sequence induction in conditions like GERD and patients with a full stomach and anticipated difficult airways.

\section{Appendices}

Author Contribution: Study Design: Laxman K. Senapati, Pulak P. Padhi. Study Registration: Krishna P. Battini. Patient Recruitment and Data Collection: Laxman K. Senapati, Krishna P. Battini. Clinical Operation: Laxman K. Senapati, Pulak P. Padhi. Manuscript Writing and Statistical Analysis: Priyadarsini Samanta, Laxman K. Senapati.

\section{Additional Information \\ Disclosures}

Human subjects: Consent was obtained or waived by all participants in this study. Institutional Ethics Committee, Kalinga Institute of Medical Sciences, KIIT Deemed to be University, Bhubaneswar. issued approval KIIT/KIMS/IEC/ 128 /2019. This study has been approved by the Institutional Ethics Committee, Kalinga Institute of Medical Sciences, KIIT Deemed to be University, Bhubaneswar. Animal subjects: All authors have confirmed that this study did not involve animal subjects or tissue. Conflicts of interest: In compliance with the ICMJE uniform disclosure form, all authors declare the following: Payment/services info: All authors have declared that no financial support was received from any organization for the submitted work. Financial relationships: All authors have declared that they have no financial relationships at present or within the previous three years with any organizations that might have an interest in the submitted work. Other relationships: All authors have declared that there are no other relationships or activities that could appear to have influenced the submitted work.

\section{References}

1. Wright PM, Caldwell JE, Miller RD: Onset and duration of rocuronium and succinylcholine at the adductor pollicis and laryngeal adductor muscles in anesthetized humans. Anesthesiology. 1994, 81:1110-5. 10.1097/00000542-199411000-00004

2. Kumar M, Talwar N, Goyal R, Shukla U, Sethi A: Effect of magnesium sulfate with propofol induction of anesthesia on succinylcholine-induced fasciculations and myalgia. J Anaesthesiol Clin Pharmacol. 2012, 28:81-5. 10.4103/0970-9185.92451

3. Hegarty P: Postoperative muscle pains. Br J Anaesth. 1956, 28:209-12. 10.1093/bja/28.5.209

4. Brodsky JB, Ehrenwerth J: Postoperative muscle pains and suxamethonium . Br J Anaesth. 1980, 52:215-8. 10.1093/bja/52.2.215

5. Bourne JG, Collier HO, Somers GF: Succinylcholine (succinoylcholine), muscle-relaxant of short action. Lancet. 1952, 1:1225-9. 10.1016/s0140-6736(52)92058-8

6. van den Berg AA, Iqbal S: Post suxamethonium myalgia--will we never learn?. Anaesth Intensive Care. 1996, 24:116-7.

7. Spence D, Domen-Herbert R, Boulette E, Olson RL, Vacchiano C, Maye J: A comparison of rocuronium and lidocaine for the prevention of postoperative myalgia after succinylcholine administration. AANA J. 2002, 70:367-72.

8. Kahraman S, Ercan S, Aypar U, Erdem K: Effect of preoperative i.m. administration of diclofenac on suxamethonium-induced myalgia. Br J Anaesth. 1993, 71:238-41. 10.1093/bja/71.2.238

9. Joshi GP, Hailey A, Cross S, Thompson-Bell G, Whitten CC: Effects of pretreatment with cisatracurium, rocuronium, and d-tubocurarine on succinylcholine-induced fasciculations and myalgia: a comparison with placebo. J Clin Anesth. 1999, 11:641-5. 10.1016/s0952-8180(99)00109-9

10. Hochhalter CM: Evaluation of succinylcholine-induced fasciculations and myalgias with or without atracurium pretreatment. AANA J. 1996, 64:336-40. 
11. Kim KN, Kim KS, Choi HI, Jeong JS, Lee HJ: Optimal precurarizing dose of rocuronium to decrease fasciculation and myalgia following succinylcholine administration. Korean J Anesthesiol. 2014, 66:451-6. 10.4097/kjae.2014.66.6.451

12. Fatemeh H, Mojgan R: Comparison of atracurium and "mini-dose" succinylcholine for preventing succinylcholine-induced muscle fasciculations: a randomized, double-blind, placebo-controlled study. Acta Anaesthesiol Taiwan. 2010, 48:28-32. 10.1016/S1875-4597(10)60006-9

13. Sosis M, Broad T, Larijani GE, Marr AT: Comparison of atracurium and d-tubocurarine for prevention of succinylcholine myalgia. Anesth Analg. 1987, 66:657-9.

14. Erkola O: Effects of precurarisation on suxamethonium-induced postoperative myalgia during the first trimester of pregnancy. Acta Anaesthesiol Scand. 1990, 34:63-7. 10.1111/j.1399-6576.1990.tb03043.x

15. Ferres CJ, Mirakhur RK, Craig HJ, Browne ES, Clarke RS: Pretreatment with vecuronium as a prophylactic against post-suxamethonium muscle pain. Comparison with other non-depolarizing neuromuscular blocking drugs. Br J Anaesth. 1983, 55:735-41. 10.1093/bja/55.8.735

16. Booij LH, Knape HT: The neuromuscular blocking effect of Org 9426. A new intermediately-acting steroidal non-depolarising muscle relaxant in man. Anaesthesia. 1991, 46:341-3. 10.1111/j.1365-2044.1991.tb09539.x

17. Hernández-Palazón J, Noguera-Velasco J, Falcón-Araña LF, Doménech-Asensi P, Burguillos-López S, Nuño de la Rosa-Carrillo V: Precurarization with rocuronium prevents fasciculations and biochemical changes after succinylcholine administration. (Article in Spanish). Rev Esp Anestesiol Reanim. 2004, 51:184-9.

18. Schreiber JU, Lysakowski C, Fuchs-Buder T, Tramèr MR: Prevention of succinylcholine-induced fasciculation and myalgia: a meta-analysis of randomized trials. Anesthesiology. 2005, 103:877-84. 10.1097/00000542-200510000-00027

19. Foster CA: Muscle pains that follow administration of suxamethonium . Br Med J. 1960, 2:24-5. 10.1136/bmj.2.5191.24

20. Lund I, Stovner J: Dose-response curves for tubocurarine, alcuronium and pancuronium . Acta Anaesthesiol Scand Suppl. 1969, 37:238-42. 10.1111/j.1399-6576.1970.tb00916.x

21. White DC: Observations on the prevention of muscle pains after suxamethonium . Br J Anaesth. 1962, 34:332-5. 10.1093/bja/34.5.332

22. Bennetts FE, Khalil KI: Reduction of post-suxamethonium pain by pretreatment with four non-depolarizing agents. Br J Anaesth. 1981, 53:531-6. 10.1093/bja/53.5.531

23. Wig J, Bali IM: Relation of precurarization to suxamethonium to provide ease of intubation and to prevent post-suxamethonium muscle pains. Can Anaesth Soc J. 1979, 26:94-8. 10.1007/BF03013776

24. Fukano N, Suzuki T, Ishikawa K, Mizutani H, Saeki S, Ogawa S: A randomized trial to identify optimal precurarizing dose of rocuronium to avoid precurarization-induced neuromuscular block. J Anesth. 2011, 25:200-4. 10.1007/s00540-010-1086-Z

25. Subramaniam K, Subramaniam B, Patel SK: Precurarization with rocuronium-a systematic review. Anesthesiology. 2002, 96:1-5. 10.1097/00000542-200209002-00992

26. Pinchak AC, Smith CE, Shepard LS, Patterson L: Waiting time after non-depolarizing relaxants alter muscle fasciculation response to succinylcholine. Can J Anaesth. 1994, 41:206-12. 10.1007/BF03009832

27. Stoelting RK, Peterson C: Adverse effects of increased succinylcholine dose following d-tubocurarine pretreatment. Anesth Analg. 1975, 54:282-8. 10.1213/00000539-197505000-00003

28. Brodsky JB, Brock-Utne JG, Samuels SI: Pancuronium pretreatment and post-succinylcholine myalgias. Anesthesiology. 1979, 51:259-61. 10.1097/00000542-197909000-00017

29. Bowman WC: Prejunctional and postjunctional cholinoceptors at the neuromuscular junction. Anesth Analg. 1980, 59:935-43.

30. Joshi JVS, Kiran TV, Satish DG: Comparative study of pretreatment with rocuronium and vecuronium in post succinylcholine fasciculation, intubation condition and myalgia. J Evol Med Dent Sci. 2016, 5:2319-24. 10.14260/jemds/2016/539

31. Abbas N, Tariq S, Khan AW, Murtaza G, Naqvi N, Khanzada A: To asses the effects of rocuronium pretreatment on succinylcholine induced fasciculations and postoperative myalgias. J Pak Med Assoc. 2009, 59:847-50.

32. Abraham V, Kumar AR, Afzal L: Evaluation of post succinylcholine myalgia and intubation conditions with rocuronium pretreatment: a comparison with vecuronium. Indian J Anaesth. 2008, 52:2-6.

33. Demers-Pelletier J, Drolet P, Girard M, Donati F: Comparison of rocuronium and d-tubocurarine for prevention of succinylcholine-induced fasciculations and myalgia. Can J Anaesth. 1997, 44:1144-7. 10.1007/BF03013334

34. Findlay GP, Spittal MJ: Rocuronium pretreatment reduces suxamethonium-induced myalgia: comparison with vecuronium. Br J Anaesth. 1996, 76:526-9. 10.1093/bja/76.4.526

35. Martin R, Carrier J, Pirlet M, Claprood Y, Tétrault JP: Rocuronium is the best non-depolarizing relaxant to prevent succinylcholine fasciculations and myalgia. Can J Anaesth. 1998, 45:521-5. 10.1007/BF03012701

36. O'Sullivan EP, Williams NE, Calvey TN: Differential effects of neuromuscular blocking agents on suxamethonium-induced fasciculations and myalgia. Br J Anaesth. 1988, 60:367-71. 10.1093/bja/60.4.367

37. Tsui BC, Reid S, Gupta S, Kearney R, Mayson T, Finucane B: A rapid precurarization technique using rocuronium. Can J Anaesth. 1998, 45:397-401. 10.1007/BF03012573

38. Waters DJ, Mapleson WW: Suxamethonium pains: hypothesis and observation. Anaesthesia. 1971, 26:12741. 10.1111/j.1365-2044.1971.tb04753.x 